\title{
MICROWAVE-ASSISTED VERSATILE HYDROGENATION OF CARBONYL COMPOUNDS USING SUPPORTED METAL NANOPARTICLES
}

Maria Jose Gracia, Juan Manuel Campelo, Maria Dolores Gracia, Elia Losada, Rafael Luque, Jose Maria Marinas and Antonio Angel Romero

Organic Chemistry Deparment, University of Córdoba, Campus of Rabanales, Marie CurieBuidingl (C3), Ctra Nnal IV,Km396, E-14014 Córdoba, Spain. E-mail:

marijosegt@hotmail.com

The efficient microwave-assisted transfer hydrogenation of carbonyl compounds was performed using supported Pt and Pd nanoparticles on Al-SBA-15 materials. Excellent conversions, with exceedingly higher TOF values $\left(4,000-20,000 \mathrm{~h}^{-1}\right)$ compared to any previous literature report, were achieved in very short times of reaction (5-30 $\mathrm{min}$ ), together with complete selectivities to the hydrogenated product<smiles>CC(=O)c1ccccc1</smiles><smiles>CC(O)c1ccccc1</smiles> 